Chapman University

Chapman University Digital Commons

Food Science Faculty Articles and Research

Food Science

2015

\title{
Microbial Safety and Quality of Fresh Herbs from Los Angeles, Orange County, and Seattle Farmers' Markets
}

Donna J. Levy

Chapman University

Nicola K. Beck

University of Washington - Seattle Campus

Alexandra L. Kossick

University of Washington - Seattle Campus

Taylor Patti

Chapman University

J. Scott Meschke

University of Washington - Seattle Campus

See next page for additional authors

Follow this and additional works at: http://digitalcommons.chapman.edu/food_science_articles Part of the Food Microbiology Commons

\section{Recommended Citation}

Levy, D. J., Beck, N. K., Kossik, A. L., Patti, T., Meschke, J. S., Calicchia, M. and Hellberg, R. S. (2015), Microbial safety and quality of fresh herbs from Los Angeles, Orange County and Seattle farmers' markets. J. Sci. Food Agric., 95: 2641-2645. doi: 10.1002/jsfa.6996

This Article is brought to you for free and open access by the Food Science at Chapman University Digital Commons. It has been accepted for inclusion in Food Science Faculty Articles and Research by an authorized administrator of Chapman University Digital Commons. For more information, please contact laughtin@chapman.edu. 


\section{Microbial Safety and Quality of Fresh Herbs from Los Angeles, Orange County, and Seattle Farmers' Markets}

\section{Comments}

This is the accepted, peer-reviewed version of the following article:

Levy, D. J., Beck, N. K., Kossik, A. L., Patti, T., Meschke, J. S., Calicchia, M. and Hellberg, R. S. (2015), Microbial safety and quality of fresh herbs from Los Angeles, Orange County and Seattle farmers' markets. J. Sci. Food Agric., 95: 2641-2645. doi: 10.1002/jsfa.6996

which has been published in final form at DOI: 10.1002/jsfa.6996. This article may be used for noncommercial purposes in accordance with Wiley Terms and Conditions for Self-Archiving.

\section{Copyright}

Society of Chemical Industry

\section{Authors}

Donna J. Levy, Nicola K. Beck, Alexandra L. Kossick, Taylor Patti, J. Scott Meschke, Melissa Calicchia, and Rosalee S. Hellberg 
1 Running title: Microbial Safety and Quality of Fresh Herbs from Farmers' Markets...

5 Authors: Donna J. Levy ${ }^{1}$, Nicola K. Beck ${ }^{2}$, Alexandra L. Kossik ${ }^{2}$, Taylor Patti ${ }^{1}$, J. Scott

6 Meschke $^{2}$, Melissa Calicchia ${ }^{3}$, and Rosalee S. Hellberg ${ }^{1 *}$

$8 \quad{ }^{1}$ Chapman University, Schmid College of Science and Technology, Food Science and

9 Nutrition, One University Drive, Orange, CA 92866

$10 \quad{ }^{2}$ University of Washington, School of Public Health, Seattle, WA

$11{ }^{3}$ Food Safety Solutions and Food Microbiological Laboratories, 10653 Progress Way, Cypress,

12 CA 90630

13

14 Keywords: Basil, parsley, cilantro, farmers' markets, Salmonella, Escherichia coli

16 *Corresponding Author:

17 Rosalee S. Hellberg

18 Ph: 714-628-2811

19 E-mail: hellberg@chapman.edu 
Abstract

24 BACKGROUND: Farmers' markets have been growing in popularity in the United States, but

25 the microbial quality and safety of the food sold at these markets is currently unknown. The

26 purpose of this study was to assess the microbial safety and quality of fresh basil, parsley, and

27 cilantro sold at farmers' markets in the Los Angeles, Orange County, and greater Seattle areas.

28 RESULTS: A total of 133 samples (52 basil, 41 cilantro, and 40 parsley) were collected from 13

29 different farmers' markets and tested for Salmonella and generic Escherichia coli. One sample

30 (parsley) was confirmed positive for Salmonella and $24.1 \%$ of the samples were positive for

31 generic E. coli, with a range of 0.70-3.15 $\log$ CFU/g. Among the herbs tested, basil showed the

32 highest percentage of samples with generic E. coli $(26.9 \%)$, followed by cilantro (24.4\%), and

33 then parsley (20.0\%). For $12 \%$ of samples, the levels of generic E. coli exceeded guidelines

34 established by the Public Health Laboratory Service for microbiological quality of ready-to-eat

35 foods.

36 CONCLUSION: Overall, this study indicates the presence of Salmonella and generic E. coli in

37 fresh herbs sold at farmers' markets; however, additional studies are needed to determine the 38 sources and extent of contamination. 
Introduction

Farmers' markets have become an important source of produce for many consumers in

the United States. ${ }^{1}$ These markets are generally held in the summer months and allow for

49 consumers to purchase locally grown fruits and vegetables directly from the producer or farmer.

50 According to the United States Department of Agriculture (USDA) Economic Research Service,

51 farmers' markets have been increasing since 2009 near urban areas, particularly along the East

52 and West coasts. ${ }^{1}$ In August 2013 there were over 8,000 farmers' markets listed in the USDA's

53 National Farmers' Market directory, a 3.6\% increase from $2012 .^{2}$ While farmers' markets can

54 become certified to ensure that each farmer is actually growing the commodities being sold,

55 food safety is not addressed as part of the certification process. Some potential areas of concern

56 with regard to food safety at these markets are the storage conditions of the produce throughout

57 the day, the farming practices, and the farmer's pre- and post- harvest handling techniques.

Certain herbs, such as parsley, basil, and cilantro have been implicated in many food

59 outbreaks over the past two decades. ${ }^{3-6}$ In 1999, there were 41 restaurant-associated illnesses

60 and 35 sporadic cases involving Salmonella enterica serotype Thompson in fresh, room

61 temperature cilantro that was suspected to originate from Mexico. ${ }^{5}$ In 2006, about 200 teachers

62 and students in Denmark were infected with Salmonella and enterotoxigenic Escherichia coli

63 (ETEC) from the consumption of a pasta salad with pesto. ${ }^{3}$ A retrospective cohort study

64 determined that fresh basil used in the preparation of the pesto was most likely the source of

65 illness due to contamination with ETEC and S. enterica serotype Anatum. ${ }^{3}$ Furthermore, in

66 2007, Salmonella was found in 18 out of 3,760 ready-to-eat fresh herb samples collected from

67 different retail stores and tested by 30 laboratories in the UK. ${ }^{6}$ Eight of the 18 contaminated

68 samples consisted of fresh basil obtained from a single grower in Israel. ${ }^{4,6}$ Increasing concern 
69 over foodborne outbreaks in fresh produce has also led to testing for generic E. coli as an

70 indicator of fecal contamination and potential pathogen presence. ${ }^{7}$ Fecal contamination in fresh

71 herbs and other types of fresh produce is problematic, as these items are commonly consumed

72 raw, with no intervention step to inactivate potential pathogens.

73 There is currently limited information on food safety at farmers' markets and some

74 studies conducted thus far have reported concerning results..$^{8-10}$ For example, a study in

75 Pennsylvania, USA, reported the presence of Salmonella and Campylobacter in raw chicken

76 sold at farmers' markets at detection frequencies of $28 \%$ and $90 \%$, respectively. ${ }^{9}$ In

77 comparison, raw chicken samples from conventional supermarkets showed detection

78 frequencies of $8-20 \%$ for Salmonella and $28-52 \%$ for Campylobacter. Teng et al. ${ }^{10}$ investigated

79 the food handling practices of cheese vendors at farmers' markets located in Ontario, Canada. It

80 was found that $47 \%$ of the vendors had problems with refrigeration and a majority of the

81 vendors did not wash their hands prior to handling the cheese. Furthermore, a study surveying

82 supermarkets and farmers' markets in Ontario, Canada, reported the presence of thermotolerant

83 Campylobacter spp. in a number of fresh produce items sold at the farmers' markets, including

84 parsley, and no detections in fresh produce items sold at the supermarkets. ${ }^{8}$ Despite the

85 potential for foodborne illness from fresh herbs and other fresh produce sold at farmers' markets

86 in the United States, there is currently a lack of knowledge regarding the microbial safety and

87 quality of these items.

88 Due to the prevalence of farmers' markets along the U.S. West Coast and the association

89 of fresh herbs with outbreaks of foodborne illness, the overall objective of this study was to

90 conduct a survey of the microbial safety and quality of fresh basil, parsley, and cilantro sold at 
91 farmers' markets in the Los Angeles, Orange County and greater Seattle areas. Specifically, the

92 fresh herbs were tested for Salmonella, E. coli, and total coliforms.

94 Media and bacterial strains. Unless otherwise stated, all media were obtained from Hardy

95 Diagnostics (Santa Maria, CA, USA). For the Los Angeles County, CA, and Orange County,

96 CA, portion of the study, S. enterica serotype Abaetetuba ATCC 35640 and generic E. coli

97 ATCC 51813 were used as positive control strains. For the greater Seattle area, WA, portion of

98 the study an environmental S. enterica isolate, S. enterica LT2 (courtesy of the laboratory of Dr.

99 Sobsey at the University of North Carolina, Chapel Hill, USA), and generic E. coli ATCC

10011303 were used as positive controls.

101 Sample collection. Thirteen different farmers' markets were visited in the Los Angeles,

102 Orange County and greater Seattle areas (Table 1), and a total of 133 samples of basil, parsley,

103 and cilantro were aseptically collected from the display tables using plastic sampling bags.

104 Farmers' markets were selected on the basis of geographical proximity to the research

105 laboratories to allow for samples to be analyzed on the same day that they were collected. The

106 number of samples collected was determined based on budgetary constraints as well as the

107 availability of samples at farmers' markets. Sample collection took place between 8 and 10 am

108 in Orange and Los Angeles Counties and between 10:30 am and 2:30 pm in the greater Seattle

109 area. Samples were collected between July and October 2013 and each farmers' market was

110 visited between 1 and 3 times depending on sample availability (Table 1). Each sample unit

111 collected was equivalent to at least 454 grams (1 pound). ${ }^{11}$ Following sample collection, herbs

112 were transported on ice in a cooler to the laboratory at Chapman University (Orange, CA, USA) 
113 or the University of Washington (Seattle, WA, USA), where they were prepared according to

114 the methods described in succeeding sections.

115 Salmonella testing of fresh herbs. Samples were prepared for Salmonella testing according to

116 the U.S. Food and Drug Administration (FDA) Bacteriological Analytical Manual (BAM). ${ }^{12}$

117 Twenty-five grams of each herb sample were aseptically weighed into $24 \mathrm{oz}$. Whirl-Pak bags

118 (Nasco, Fort Atkinson, WI, USA). Lactose broth (225 ml) was added and mixed by vigorously

119 swirling the bag 25 times clockwise and then counterclockwise. The samples were incubated for

$12024 \pm 2 \mathrm{~h}$ at $35 \pm 2{ }^{\circ} \mathrm{C}$. Then, $0.1 \mathrm{ml}$ of each sample was transferred to a test tube containing 10

$121 \mathrm{ml}$ of Rappaport Vassiliadis (RV) broth and $1.0 \mathrm{ml}$ of each sample was transferred to a test tube

122 containing $10 \mathrm{ml}$ tetrathionate (TT) broth. The inoculated RV and TT tubes were incubated for

$12324 \pm 2 \mathrm{~h}$ at $42 \pm 1{ }^{\circ} \mathrm{C}$. Next, a sterile inoculating loop was used to streak samples from the RV

124 and TT tubes onto individual plates of xylose lysine deoxycholate (XLD), bismuth sulfite (BS),

125 and hektoen enteric (HE) agar for isolation, resulting in six plates per sample. The plates were

126 inverted and incubated for $24 \pm 2 \mathrm{~h}$ at $35 \pm 2{ }^{\circ} \mathrm{C}$.

127 After incubation, typical Salmonella colonies were selected from XLD, BS, and HE agar

128 plates and confirmed, as described below. Typical colonies on XLD agar appear pink with or

129 without black centers. ${ }^{12}$ Typical colonies on BS agar appear brown, gray or black with an

130 occasional metallic sheen, and typical colonies on HE agar appear blue to blue-green with or

131 without black centers. In the absence of typical colonies on HE and XLD after $24 \pm 2 \mathrm{~h}$

132 incubation, one atypical Salmonella colony was selected per sample for confirmation testing. If

133 typical or suspicious colonies were not present on BS agar after $24 \pm 2 \mathrm{~h}$, the plates were re-

134 incubated for an additional $24 \pm 2 \mathrm{~h}$. If typical or suspicious colonies were not present after 48

$135 \pm 2 \mathrm{~h}$ incubation, then one atypical colony was selected per sample for confirmation testing. ${ }^{12}$ 
136 The colonies were transferred to triple sugar iron (TSI) agar and lysine iron agar (LIA) slants

137 and incubated at $35 \pm 2{ }^{\circ} \mathrm{C}$ for $24 \pm 2 \mathrm{~h}$. Samples showing typical TSI/LIA slants were then

138 confirmed with API 20E test kits (bioMérieux, Durham, NC, USA).

139 Generic Escherichia coli and total coliform testing of fresh herbs. Herbs were tested for

140 generic E. coli and total coliforms according to the Association of Official Analytical Chemists

141 Method 991.14. ${ }^{13}$ Samples (50 g each) were aseptically weighed into Whirl-Pak bags and 450

$142 \mathrm{ml}$ of Butterfield's phosphate buffer was added. Samples were then mixed at $230 \mathrm{rpm}$ for $30 \mathrm{~s}$

143 in a Stomacher 400 Circulator (Seward, Norfolk, UK). Each sample was plated in duplicate by

144 pipetting $1 \mathrm{ml}$ of the sample homogenate onto an E. coli/Coliform Petrifilm plate (3M, Saint

145 Paul, MN, USA). The Petrifilm plates were incubated at $35 \pm 2{ }^{\circ} \mathrm{C}$ for $48 \pm 2 \mathrm{~h}$ in stacks of 20

146 or less and then enumerated for E. coli and total coliforms. The average E. coli and total

147 coliform counts were determined for each sample. In cases where the number of colonies was

148 outside of the countable range of 15-150, an estimated plate count was obtained.

149 Statistical analyses. The levels of E. coli and total coliforms were statistically compared across

150 herb types using a one-way analysis of variance (ANOVA), with a predetermined significance

151 level of $\mathrm{p}<0.05$. The percentages of samples that were positive for E. coli and total coliforms

152 were compared across herb types with a Pearson's chi-square test, with a pre-determined 2-

153 sided significance value of $\mathrm{p}<0.05$. All statistical analyses were carried out using IBM SPSS

154 Statistics 21 (IBM SPSS Inc., Armonk, NY, USA).

\section{Results and Discussion}

156 Sample collection. Overall, 133 samples of fresh herbs were collected for testing from 13

157 different farmers' markets (Table 1). Samples were collected from 49 different vendors at these

158 markets, with an average of 3 samples collected per vendor. Among the samples collected, 
159 basil represented the highest percentage (39\%), followed by parsley (30\%), and then cilantro

160 (31\%). Figure 1 provides a breakdown of the number of each type of herb collected within the

161 three major geographic sampling regions of Orange County, Los Angeles, and the greater

162 Seattle areas. The greatest number of samples was collected in Orange County, CA $(n=68)$,

163 followed by the greater Seattle area, WA $(n=41)$, and Los Angeles County, CA ( $n=24)$.

164 Salmonella results. Of the 133 samples collected, 15 samples had typical or suspicious growth 165 on HE, XLD, and/or BS agar. However, only one sample confirmed positive for Salmonella on 166 TSI/LIA and the API 20E test strip. This was a sample of parsley collected from a Los Angeles

167 County farmers' market (LA1) that showed typical growth on both HE and XLD agars.

168 According to the biochemical reactions, the profile given on the API 20E test strip was 6704752

169 with $99.9 \%$ identification of Salmonella spp. The remaining 118 samples either showed no

170 growth or atypical colonies on HE, XLD, and BS agars. These samples were ruled out as

171 negative with the TSI/LIA slants and, when necessary, an API 20E test strip.

172 The overall prevalence of Salmonella in parsley was $2.5 \%$. The prevalence of

173 Salmonella in fresh herbs found in this study was similar to percentages reported previously for

174 Salmonella in FDA field investigation studies. ${ }^{11,14}$ These studies reported Salmonella

175 prevalence rates of $0-2.5 \%$ in imported and domestic parsley samples and $1.2-9 \%$ in imported

176 and domestic cilantro samples. The FDA studies each collected 84-90 samples of parsley and

177 85-177 samples of cilantro, compared to 40 parsley samples and 41 cilantro samples collected

178 in the current study. Further testing of these herbs from farmers' markets will be useful in

179 verifying Salmonella prevalence. Although it is not known whether the Salmonella detected

180 was present at infectious levels, contamination of fresh herbs with Salmonella is concerning

181 considering that these herbs are commonly consumed raw. Salmonellosis symptoms include: 
182 diarrhea, abdominal cramps, and fever about 12 to 72 hours after consumption that lasts about

183 four to seven days. ${ }^{15}$ In severe cases, the diarrhea may be so detrimental that the patients must

184 be hospitalized because the infection can spread from the intestines to the blood stream and

185 other sites in the body. The severe illness generally occurs in the elderly, infants and those with

186 compromised immune systems. Overall, the results of the current study illustrate the possibility

187 of Salmonella contamination in fresh herbs sold at farmers' markets and demonstrate a need for

188 more extensive investigation into this topic.

189 Generic Escherichia coli and total coliform results. Among the 133 fresh herb samples

190 tested in this study, $24.1 \%$ were positive for generic E. coli (Fig. 1) and $84.2 \%$ were positive for

191 total coliforms, with a range of 0.70-3.15 and 0.70-4.15 log CFU/g, respectively (Table 2).

192 Interestingly, the parsley sample found to be positive for Salmonella was positive for total

193 coliform growth $(0.70 \log \mathrm{CFU} / \mathrm{g})$ but not for E. coli. The average generic E. coli count for all

194 positive samples combined was $1.81 \log \mathrm{CFU} / \mathrm{g}$ and the average total coliform count was 2.45

$195 \log \mathrm{CFU} / \mathrm{g}$. There were no significant differences in levels of $E$. coli or total coliforms when

196 compared across the three types of herbs tested, according to a one-way ANOVA, with

197 significance set at $\mathrm{p}<0.05$. A total of 16 samples had average $E$. coli counts considered to be

198 unsatisfactory ( $\geq 2 \log$ CFU/g) according to guidelines established by the Public Health

199 Laboratory Service for microbiological quality of ready-to-eat foods. ${ }^{16}$ The herbs in this

200 category included seven basil samples, five cilantro samples, and four parsley samples. These

201 samples were collected from two farmers' markets in Orange County, CA (OC1 and OC2), two

202 farmers' markets in the greater Seattle area ( $\mathrm{SC} 1$ and $\mathrm{KC} 3$ ), and one farmers' market in Los

203 Angeles County, CA (LA2). Among the herbs tested, basil showed the highest percentage of

204 samples with growth for generic E. coli (26.9\%), followed by cilantro (24.4\%) and then parsley 
$205(20.0 \%)$. On the other hand, cilantro showed the greatest percentage of samples positive for 206 total coliforms (87.8\%), followed by basil (82.7\%), and parsley (82.5\%). There were no 207 significant differences in the percentage of samples positive for E. coli or total coliforms across 208 herb types, according to a Pearson's chi-square test with significance set at $\mathrm{p}<0.05$. As shown 209 in Fig. 1, Orange County farmers' markets had the highest percentage of samples with E. coli 210 growth, at $26.5 \%$, followed by farmers' markets in the greater Seattle area (24.4\%), and Los 211 Angeles County farmers' markets (16.7\%). The percentages of positive samples were not 212 statistically compared across locations due to differences in sample sizes.

213 Although generic E. coli are generally more useful than total coliforms as indicators of 214 fecal contamination in fresh produce, total coliform levels were also recorded in this study in 215 order to enable comparison with existing research on microbiological quality of fresh herbs. In 216 general, the levels and detection frequencies of generic E. coli and total coliforms in the current

217 study were similar to or higher than those found in previous studies examining the 218 microbiological quality of fresh herbs. For example, in a series of two studies, Johnston et $219 a{ }^{17}{ }^{1718}$ reported average levels of generic E. coli to be $0.70-1.31 \log$ CFU/g and total coliform 220 levels to be 1.3-3.4 log CFU/g for commercially grown parsley $(n=141)$ and cilantro samples $221(\mathrm{n}=187)$ collected during multiple steps in the production and packaging process. In 222 comparison, average levels of $1.82 \log \mathrm{CFU} / \mathrm{g}$ (generic E. coli) and $2.36 \log \mathrm{CFU} / \mathrm{g}$ (total 223 coliforms) were found in the current study for these two herbs combined (excluding basil).

224 Furthermore, Allen et al. ${ }^{19}$ tested a variety of herb samples $(\mathrm{n}=61)$, including basil and 225 cilantro, sold at retail stores in five Canadian cities and found that only $6.6 \%$ of the samples 226 showed E. coli growth and $37.7 \%$ of the samples showed growth of total coliforms, compared to $22724.1 \%$ and $84.2 \%$, respectively, in the current study. However, the average total coliform 
228 counts of 1.3 to $2.6 \log$ CFU/g reported by Allen et al. ${ }^{19}$ were similar to those observed in the

229 current study for all herbs combined (2.45 $\log \mathrm{CFU} / \mathrm{g})$. Finally, a study by Arthur et al. ${ }^{20}$ also

230 found lower detection frequencies of generic E. coli in fresh herbs sold at retail distribution

231 centers and farmers' markets in Ontario, Canada, with growth in $13.4 \%$ of parsley samples $(\mathrm{n}=$

$232127)$ and $4.9 \%$ of cilantro samples $(n=61)$. Interestingly, the authors reported $E$. coli to be

233 present at higher maximum levels in these herbs as compared to the current study, with up to

$2344.2 \log \mathrm{CFU} / \mathrm{g}$ found in parsley and up to $3.9 \log \mathrm{CFU} / \mathrm{g}$ found in cilantro, compared to up to

$2353.15 \log \mathrm{CFU} / \mathrm{g}$ in parsley and up to $2.66 \log \mathrm{CFU} / \mathrm{g}$ in cilantro found in the current study

236 (Table 2).

237 Overall, the majority of fresh herb samples tested in the present study were compliant

238 with microbiological criteria established by the Public Health Laboratory Service for

239 microbiological quality of ready-to-eat foods; however, $12 \%$ of samples showed levels of

240 generic E. coli determined to be unsatisfactory by these guidelines. Further research is needed

241 to determine the source(s) of contamination and whether contamination is greater at farmers'

242 markets compared to other retail sources of fresh produce.

\section{Conclusions}

244 With the growing popularity of farmers' markets, the lack of food safety regulations at

245 these markets, and the association of fresh produce with foodborne illness, it has become

246 increasingly important to monitor the microbiological safety and quality of these items.

247 Overall, a relatively high level of microbiological contamination was found in the herbs

248 collected in this study as compared to previous studies. However, additional studies are needed

249 to verify this trend. While a direct comparison between fresh herbs from farmers' markets and

250 conventional supermarkets was not carried out in this study, storing herbs at ambient 
251 temperatures in the open environment during warm summer days could impact the

252 microbiological safety and quality of these items. At conventional supermarkets, fresh herbs

253 and other perishable produce items are held under controlled temperature and humidity

254 conditions and they are required to be handled according to the Good Manufacturing Practices.

255 In order to assess the importance of these factors, additional research is needed comparing the

256 microbial quality and safety of herbs held in controlled environments, such as those in a

257 conventional supermarket, to those held at ambient temperatures in outdoor environments, such

258 as at a farmers' market. Since farmers' markets are generally held in the summer months,

259 another important area of research will be to monitor microbial changes that occur in fresh herbs

260 and other perishables throughout the day as the temperature increases from the morning to the

261 afternoon. The current study, along with future research in this area, will be important in

262 heightening our understanding of the safety of perishable foods sold at farmers' markets.

Acknowledgments

264 The authors thank the Schmid College of Science and Technology at Chapman

265 University for funding support and Karylin Gonzalez and the Food Microbiological Laboratory

266 team for the support and use of materials throughout this project. We also express our gratitude

267 to Lilian Were for assisting with manuscript editing.

\section{References}

269 1. USDA, Market penetration by farmers' markets varies geographically. United States

270 Department of Agriculture Economic Research Service, 2013. Available:

$271 \quad$ http://ers.usda.gov/data-products/chart-

272 gallery/detail.aspx?chartId=34796\&ref=collection\#.Ui_V-H-PeVP [11 July 2014] 
273 2. USDA, Farmers Markets and Local Food Marketing. United States Department of

274 Agriculture, 2013. Available: http://www.ams.usda.gov/AMSv1.0/farmersmarkets [10

$275 \quad$ July 2014]

276 3. Pakalniskiene J, Falkenhorst G, Lisby M, Madsen SB, Olsen KEP, Nielsen EM et al., A

277 foodborne outbreak of enterotoxigenic E. coli and Salmonella Anatum infection after a

278 high-school dinner in Denmark, November 2006. Epidemiol Infect 137:396-401 (2009).

279 4. Pezzoli L, Elson R, Little CL, Yip H, Fisher R, Yishai R, Packed with Salmonella-

280 investigation of an international outbreak of Salmonella Senftenberg infection linked to

281 contamination of prepacked basil in 2007. Foodborne Path Dis 5:661-8 (2008).

282 5. Campbell J, Mohle-Boetani J, Reporter R, Abbott S, Farrar J, Brandi M et al., An

283 outbreak of Salmonella serotype Thompson associated with fresh cilantro. J Infect Dis

$284 \quad$ 183:984-7 (2001).

285 6. Elviss NC, Little CL, Hucklesby L, Sagoo S, Surman-Lee S, di Pinna E et al.,

286 Microbiological study of fresh herbs from retail premises uncovers an international

287 outbreak of Salmonellosis. Int J Food Microbiol 134:83-8 (2009).

288 7. Mandrell RE. Enteric human pathogens associated with fresh produce: sources,

289 transport, and ecology. In: Fan X, Niemira BA, Doona CJ, Feeherry FE, Gravani RB,

290 editors. Microbial safety of fresh produce Ames, IA.: Blackwell Publishing and IFT

291 Press; 2009. p. 5-41.

292 8. Park CE, Sanders GW, Occurrence of thermotolerant campylobacters in fresh vegetables

293 sold at farmers' outdoor markets and supermarkets. Canadian Journal of Microbiology

$294 \quad 38: 313-6(1992)$. 
295 9. Scheinberg J, Doores S, Cutter CN, A microbiological comparison of poultry products

296 obtained from farmers' markets and supermarkets in Pennsylvania. J Food Safety

$297 \quad 33: 259-64(2013)$.

298 10. Teng D, Wilcock A, Aung M, Cheese quality at farmers' markets: observation of vendor 299 practices and survey of consumer perceptions. Food Control 15:579-87 (2004).

300 11. FDA, FDA Survey of Imported Fresh Produce FY 1999 Field Assignment. U.S. Food 301 and Drug Administration, 2001. Available:

302 http://www.fda.gov/Food/GuidanceRegulation/GuidanceDocumentsRegulatoryInformati $303 \quad$ on/ProducePlantProducts/ucm118891.htm [9 July 2014]

304 12. Andrews W, Jacobson A, Hammack T, Chapter 5, Salmonella, November 2011 Version.

305 U.S. Food and Drug Administration Bacteriological Analytical Manual, 2011.

$306 \quad$ Available:

$307 \quad \underline{\text { http://www.fda.gov/Food/FoodScienceResearch/LaboratoryMethods/ucm070149.htm }}$

$308 \quad$ [11 July 2014]

309 13. AOAC. Official Methods of Analysis of AOAC International. Coliform and Escherichia 310 coli Counts in Foods, Official Method 991.14. 17th ed. Gaithersburg, MD, USA: AOAC $311 \quad$ International; 2002.

312 14. FDA, FDA Survey of Domestic Fresh Produce FY 2000/2001 Field Assignment. U.S. 313 Food and Drug Administration, 2003. Available:

$314 \quad$ http://www.fda.gov/Food/GuidanceRegulation/GuidanceDocumentsRegulatoryInformati $315 \quad$ on/ProducePlantProducts/ucm118306.htm [9 July 2014]

316 15. CDC, General Information on Salmonella. Centers for Disease Control and Prevention, 317 2010. Available: http://www.cdc.gov/salmonella/general/ [2 July 2014] 
318 16. Richards J, Roberts D, Bolton F, Guidelines for the microbiological quality of some

319 ready-to-eat foods sampled at the point of sale. Commun Dis Pub Health 3:163-7

$320 \quad$ (2000).

321 17. Johnston L, Jaykus L-A, Moll D, Anciso J, Mora B, Moe C, A field study of the 322 microbiological quality of fresh produce of domestic and Mexican origin. Int J Food 323 Microbiol 112:83-95 (2006).

324 18. Johnston LM, Jaykus LA, Moll D, Martinez MC, Anciso J, Mora B et al., A field study 325 of the microbiological quality of fresh produce. Journal of Food Protection 68:1840-7 326 (2005).

327 19. Allen K, Kovacevic J, Cancarevic A, Wood J, Xu J, Bradford G et al., A

328 microbiological survey of imported produce available at retail across Canada. Int J Food $329 \quad$ Microbiol 162:135-42 (2013).

330 20. Arthur L, Jones S, Fabri M, Odumeru J, Microbial survey of selected Ontario-grown 331 fresh fruits and vegetables. J Food Prot 70:2864-7 (2007).

335 Figure 1. Number of samples collected from farmers' markets categorized by geographic 336 region and by herb type. The number of samples that tested positive for Escherichia coli 337 growth is displayed within the total sample number for each category. The greater Seattle area 338 includes data from both King and Snohomish Counties. 
Tables

Table 1. Details on farmers' markets sampled in this study

\begin{tabular}{llllll}
\hline Location & $\begin{array}{l}\text { Farmer's market } \\
\text { ID }\end{array}$ & $\begin{array}{l}\text { No. of vendors } \\
\text { collected from }\end{array}$ & $\begin{array}{l}\text { No. of times } \\
\text { visited }\end{array}$ & $\begin{array}{l}\text { No. of samples } \\
\text { collected }\end{array}$ & Months visited \\
\hline King County, WA & KC1 & 1 & 1 & 3 & August \\
King County, WA & KC2 & 1 & 1 & 3 & August \\
King County, WA & KC3 & 7 & 3 & 18 & September, October \\
King County, WA & KC4 & 3 & 3 & 7 & August, September \\
Snohomish County, WA & SC1 & 5 & 2 & 10 & August, September \\
Los Angeles County, CA & LA1 & 4 & 1 & 5 & August \\
Los Angeles County, CA & LA2 & 7 & 1 & 3 & August \\
Los Angeles County, CA & LA3 & 2 & 3 & 53 & August \\
Orange County, CA & OC1 & 13 & 2 & 8 & July, August \\
Orange County, CA & OC2 & 2 & 1 & 3 & July, August \\
Orange County, CA & OC3 & 2 & 1 & 2 & August \\
Orange County, CA & OC4 & 1 & 1 & 2 & August \\
Orange County, CA & OC5 & 1 & August \\
\hline
\end{tabular}


Table 2. Generic E. coli and total coliform levels in positive samples of basil, parsley and cilantro

\begin{tabular}{|c|c|c|c|c|c|c|}
\hline \multirow[t]{2}{*}{ Herb type } & \multicolumn{3}{|c|}{ Generic E. coli } & \multicolumn{3}{|c|}{ Total coliforms } \\
\hline & $\begin{array}{l}\text { Positive } \\
\text { samples (n) }\end{array}$ & $\begin{array}{l}\text { Average } \\
(\log C F U / g)\end{array}$ & $\begin{array}{l}\text { Range } \\
(\log C F U / g)\end{array}$ & $\begin{array}{l}\text { Positive } \\
\text { samples (n) }\end{array}$ & $\begin{array}{l}\text { Average } \\
(\log \mathrm{CFU} / \mathrm{g})\end{array}$ & $\begin{array}{l}\text { Range } \\
(\log C F U / g)\end{array}$ \\
\hline Basil & 14 & 1.79 & $0.70-2.95$ & 43 & 2.61 & $0.70-4.15$ \\
\hline Cilantro & 10 & 1.71 & $0.70-2.66$ & 36 & 2.30 & $0.70-4.08$ \\
\hline Parsley & 8 & 1.96 & $1.00-3.15$ & 33 & 2.42 & $0.70-3.75$ \\
\hline Overall & 32 & 1.81 & $0.70-3.15$ & 112 & 2.45 & $0.70-4.15$ \\
\hline
\end{tabular}




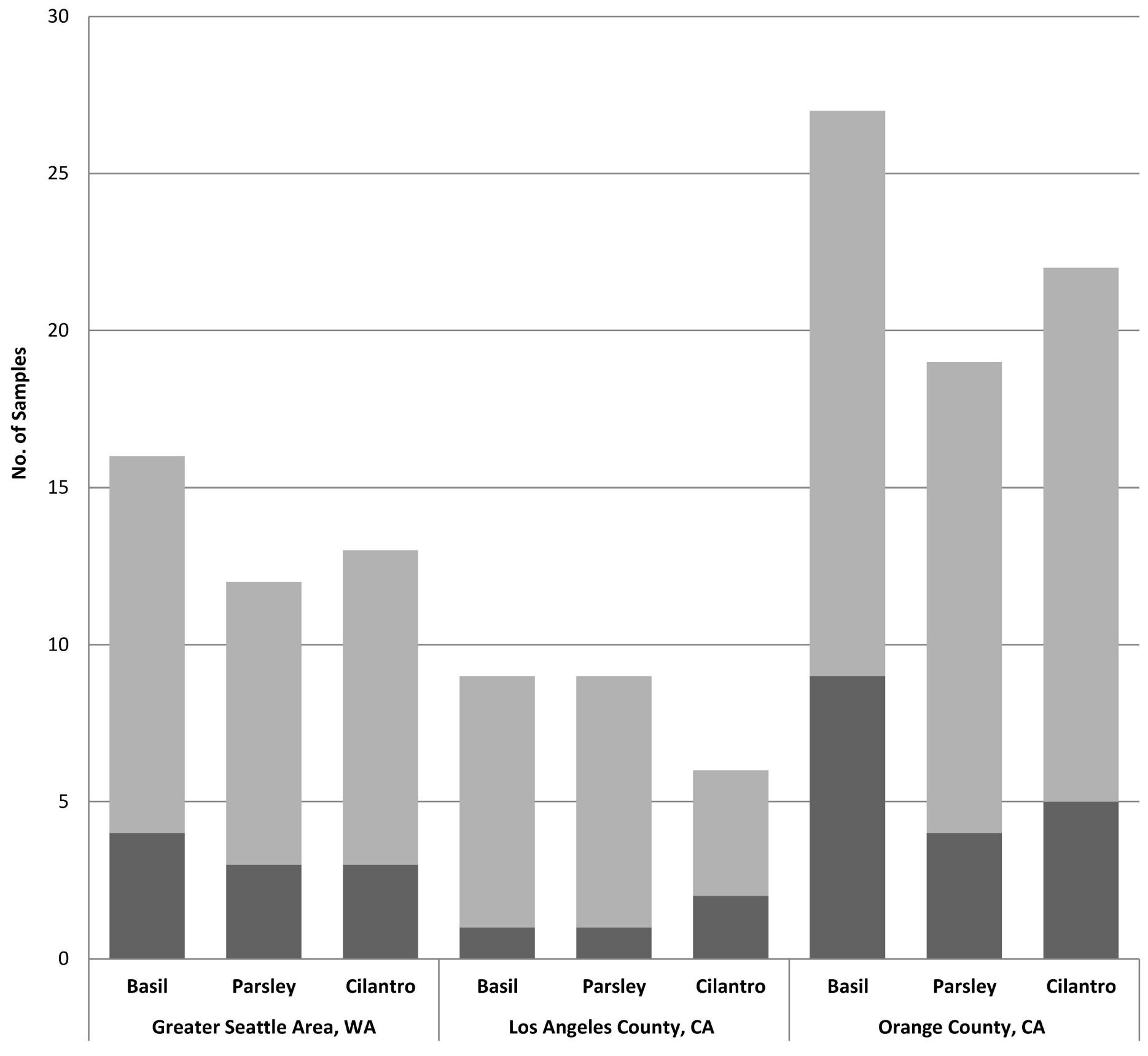

Negative for E. coli growth

nositive for E. coli growth 